Article

\title{
The Phase Evolution and Property of FeCoCrNiAlTi $x$ High-Entropy Alloying Coatings on Q253 via Laser Cladding
}

\author{
Bin $\mathrm{He}^{1,2}$, Nannan Zhang ${ }^{1, *}$ (D), Danyang Lin ${ }^{1}$, Yue Zhang ${ }^{1}$, Fuyu Dong ${ }^{1}$ and Deyuan Li ${ }^{1}$ \\ 1 Department of Material Science and Engineering, Shenyang University of Technology, Shenyang 110870, \\ China; hebin2015021@sut.edu.cn (B.H.); lindanyang2014136@sut.edu.cn (D.L.); yuezhang@sut.edu.cn (Y.Z.); \\ dongfuyu@sut.edu.cn (F.D.); dmy1962@sut.edu.cn (D.L.) \\ 2 Department of Pipeline, Shenyang Institute of Special Equipment Inspection \& Research, \\ Shenyang 110032, China \\ * Correspondence: zhangnn@sut.edu.cn; Tel.: +86-24-2549-6812
}

Received: 18 August 2017; Accepted: 25 September 2017; Published: 28 September 2017

\begin{abstract}
High-entropy alloys (HEAs) are emerging as a hot research frontier in the metallic materials field. The study on the effect of alloying elements on the structure and properties of HEAs may contribute to the progress of the research and accelerate the application in actual production. FeCoCrNiAlTi $x$ ( $x=0,0.25,0.5,0.75$, and 1 in at.\%, respectively) HEA coatings with different Ti concentrations were produced on Q235 steel via laser cladding. The constituent phases, microstructure, hardness, and wear resistance of the coatings were investigated by XRD, SEM, microhardness tester and friction-wear tester, respectively. The results show that the structure of the coating is a eutectic microstructure of $\mathrm{FCC}$ and $\mathrm{BCC}_{1}$ at $x=0$. The structure of coatings consists of both proeutectic $\mathrm{FCC}$ phase and the eutectic structure of $\mathrm{BCC}_{1}$ and $\mathrm{BCC}_{2}$. With the continuous addition of $\mathrm{Ti}$, the amount of eutectic structure decreases. The average hardness of the FeCoCrNiAlTi ${ }_{x} \mathrm{HEA}$ coatings at $x=0,0.25,0.5,0.75$, and 1 are $432.73 \mathrm{HV}, 548.81 \mathrm{HV}, 651.03 \mathrm{HV}, 769.20 \mathrm{HV}$, and $966.29 \mathrm{HV}$, respectively. The hardness of coatings increases with the addition of $\mathrm{Ti}$, where the maximum hardness is achieved for the HEA at $x=1$. The wear resistance of the HEA coatings is enhanced with the addition of $\mathrm{Ti}$, and the main worn mechanism is abrasive wear.
\end{abstract}

Keywords: laser cladding; high-entropy coatings; tribological property; phase evolution; FeCoCrNiAlTi $_{x}$

\section{Introduction}

The concept of high-entropy alloys (HEAs) is a new alloy design philosophy that was proposed recently, breaking the bottleneck stage of the conventional alloy design concept. The HEA philosophy considers that multiple principle elements in an alloy system will not produce brittle phases such as intermetallic compounds (IMCs) or other complex phases, leading to brittleness and difficulties in processing and application. On the contrary, the high entropy effect can maintain the simple solid solutions in alloys [1-3]. The main reason people think multiple principle elements will decrease the property of the alloy is the Gibbs phase rule. According to the Gibbs phase rule, $f=n-p+1(f$, freedom degree; $n$, component number; $p$, phase number), the equilibrium solidification phase number for $n$ kinds of elements is given by $p=n+1$. Since phase formation processes are always non-equilibrium solidification, the number of phases tends to be given by $p>n+1$. More precisely, as more types of principle elements are added to the alloy system, more complicated phases appear in it, which is harmful [4]. However, a new path of alloy design was carried out for the first time by Yeh et al. [5,6] in 2004. They found that there were no IMCs if more than five types of principle elements were added 
into the alloy system and simple solid solutions could be gained. More and more scholars have now joined in the study of HEAs. HEAs are better than traditional alloys in many aspects because of their high entropy effect especially in the preparation of wear and corrosion-resistant coatings, which are reported to be good candidates as structural and functional materials. Much research has been done on the properties of different HEAs. Duan et al. [7] found that the hardness of AlCoCrFeNiCu via arc melting was $475.3 \mathrm{HV}$, showing excellent tribological properties. Tian et al. [8] collected nearly 100 kinds of HEA experimental results and found that hardness steadily increased with different atomic sizes. Among the previous HEAs studied, HEAs are usually synthesized via arc melting technology or casting methods, which can result in high costs due to the amounts of expensive alloying elements that are added. As wear and corrosion resistance is a surface phenomenon and mainly determined by the surface properties of a material rather than by the bulk properties, laser cladding is widely adopted in the coating preparation since it has many advantages such as energy concentration, a low substrate dilution rate, and a fast cooling rate. Chen et al. [9] found that, with the increase in aluminum content, $\mathrm{Al}_{x} \mathrm{CoFeNiCu}_{1-x}$ HEAs displayed a greater hardness. An et al. [10] prepared $\mathrm{MoFeCrTiWAl}_{x} \mathrm{Si}_{y}$ coatings via laser cladding, which can obtain excellent quality coatings with the simultaneous addition of Si and $\mathrm{Al}$.

Many HEA compositions are possible, and one well-known system is $\mathrm{Al}-\mathrm{Fe}-\mathrm{Cr}-\mathrm{Co}-\mathrm{Ni}$. The evolution of the phase/microstructure was attributed to rapid quenching during laser processing. Alloy systems possess attractive properties such as high hardness, abrasiveness, and corrosion resistance. The addition of elements has a significant effect on the properties of HEA coatings [11,12]. It has been reported that $\mathrm{Cu}, \mathrm{Ni}$ can promote the formation of a face-centered cubic (FCC) system, while $\mathrm{Cr}$, Ti can lead to the formation of a body-centered cubic (BCC) system. The in-depth investigation on the effect of element addition on properties and structures may accelerate the application of HEA coatings. Thus, in this work, the effect of Ti addition on the properties and phase evolution of $\mathrm{FeCoCrNiAlTi}_{x}$ coatings is investigated, and the results of the present study on the rules of phase evolution, microhardness, and wear resistance would provide theoretical guidance to further explore the effects on the HEAs of other element additions.

\section{Experimental Procedure}

In this experiment, Q235 steel (SD Steel, Jinan, China) was chosen as the substrate and the nominal chemical composition in wt \% is $0.12 \%-0.2 \% \mathrm{C} ; 0.28 \% \mathrm{Cr} ; 0.2 \% \mathrm{Ni} ; 0.3 \% \mathrm{Si} ; 0.3 \%-0.67 \% \mathrm{Mn} ; 0.035 \%$ $\mathrm{S} ; 0.04 \% \mathrm{P}$ and $\mathrm{Fe}$ balance. The equiatomic ratio of the pure $\mathrm{Co}, \mathrm{Ni}, \mathrm{Cr}$, and $\mathrm{Al}$ powder mixed with various concentrations of Ti powder (99.6\%, 300 mesh, Tianjiu Ltd., Changsha, China) was chosen as the cladding powder. Fe powder was not included in the cladding powder since the Fe atoms can be introduced from the substrate due to the dilution, and the content can be regulated by controlling the power of laser. The mixed powder was ground via planetary ball mill for $10 \mathrm{~h}$ with a rotate speed of $200 \mathrm{r} / \mathrm{min}$. The ground powder was preplaced on the surface of $100 \mathrm{~mm} \times 100 \mathrm{~mm} \times 10 \mathrm{~mm}$ cleaned Q235 substrates with a thickness of $1.5 \mathrm{~mm}$. The laser generator (FL-Dlight-1500, Yuchen Ltd., Nanjing, China) was used to prepare the sample with a power of $800 \mathrm{~W}$, a scanning speed of $3 \mathrm{~mm} / \mathrm{s}$, a spot size of $3 \mathrm{~mm} \times 1 \mathrm{~mm}$, an overlap rate of $30 \%$ with Ar protection $(10 \mathrm{~L} / \mathrm{min})$, under which good quality FeCoCrNiAlTi $x(x=0,0.25,0.5,0.75$, and 1 in at. $\%$, respectively) HEA coatings of moderate dilution could be achieved. The cladded samples were cut into small cross sections for metallography. The samples were ground using a grinding machine; grinding started at 100, and then proceeded at 200 and then 2000 abrasive papers, which was followed by polishing using a $1 \mathrm{~m}$ diamond slurry. They were then etched by a $5 \%$ nitric acid alcohol solution. The scanning electronic microscope (SEM, S3400, Hitachi, Tokyo, Japan) equipped with an energy dispersive spectrometer (EDS, Hitachi) was used to observe the microstructure of coatings and determine the content of elements, while the X-ray diffraction (XRD, Shimadzu 7000, Kyoto, Japan) was used to identify the constituent phase with $\mathrm{Cu}$ $\mathrm{K} \alpha(\lambda=0.154 \mathrm{~nm})$ radiation at a step of $0.02^{\circ}$. The microhardness was tested by a Vickers hardness tester (HVS-5, Lai Hua Ltd., Laizhou, China) with a load of $200 \mathrm{~g}$ and a duration time of $10 \mathrm{~s}$. Sliding 
wear tests of the samples were performed on the universal tester by the ball-on-plate configuration under a dry condition, and the WC ball was chosen as the contact head. The friction and wear tests were carried out with a frequency of $5 \mathrm{~Hz}$ for $20 \mathrm{~min}$.

\section{Results and Discussion}

Figure 1 shows the XRD results of FeCoCrNiAlTi $x$ HEA coatings. It is obvious that both FCC and $\mathrm{BCC}_{1}$ systems exist in the $\mathrm{FeCoCrNiAl}$ coating, which can be identified as $(\mathrm{Fe}, \mathrm{Ni})$ and $\mathrm{Fe}-\mathrm{Cr}$ phases, respectively. However, the FCC system disappears in the FeCoCrNiAlTi $0_{0.25}$ HEA coating and the AlNi, which is BCC forms. Ti is a BCC stabilizing element that restrains the formation of FCC. The AlNi is identified as $\mathrm{BCC}_{2}$. Jiao et al. [13] gained a similar result in the experiment where $\mathrm{AlCoCrFeNiTi}_{x}$ was deposited via arc melting and injection into a water-cooled copper mold.

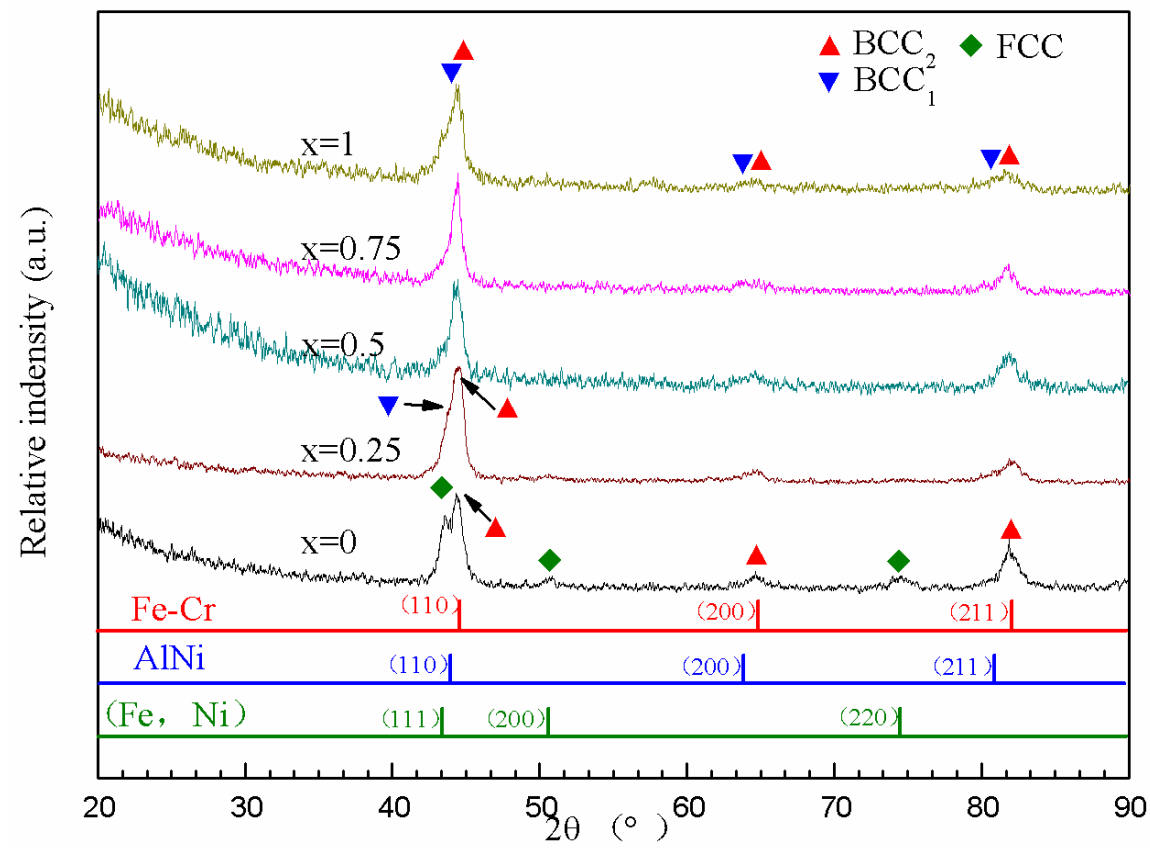

Figure 1. XRD results of FeCoCrNiAlTi $x$ high-entropy alloy (HEA) coatings.

Figure 2 shows the cross-sectional SEM images of FeCoCrNiAlTi ${ }_{x}$ HEA coatings. There are two different phases in the microstructure at $x=0$. The chemical composition in different regions, as marked in Figure 2, is listed in Table 1. It can be seen by analyzing the EDS results in Table 1 that the components of Zone A and Zone B is very similar. Thus, Zone B is a simple hole. There are only eutectic FCC and $\mathrm{BCC}_{1}$ structures here. The structure morphology changes significantly with the addition of Ti. At $x=0.25$, the structure consists of the proeutectic phase $\alpha$ and the eutectic phase $\beta$. The proeutectic phase $\alpha$ exhibits an achrysanthemum-shaped microstructure, while the eutectic phase $\beta$ is a typical lamellar. According to the EDS results shown in Table 1, it can be concluded that the content of $\mathrm{Ni}$ and $\mathrm{Al}$ is high in phase $\alpha$ and the content of $\mathrm{Fe}$ and $\mathrm{Cr}$ is high in phase $\beta$. Combined with the former XRD results, it is obvious that the phase $\alpha$ is $B C C_{1}$, while the phase $\beta$ is the eutectic phase of $\mathrm{BCC}_{1}$ and $\mathrm{BCC}_{2}$, respectively. The segregation of $\mathrm{Ni}, \mathrm{Al}, \mathrm{Fe}$, and $\mathrm{Cr}$ in different phases can be attributed to the mixing enthalpies of atomic pairs between these six elements, as it is known that the mixing enthalpies indicate a tendency to order or cluster. The mixing enthalpies represent atomic interactions between the solute elements and the base solvent. It is easy to occupy the cluster center for a solute because it shows a negative $\Delta H$ tendency and shows that a weak $\Delta H$ tends to take the glue site. Such a cluster-based formulism has been validated in many FCC and BCC alloys, which satisfies specific composition formulas in limited quantities [14]. 


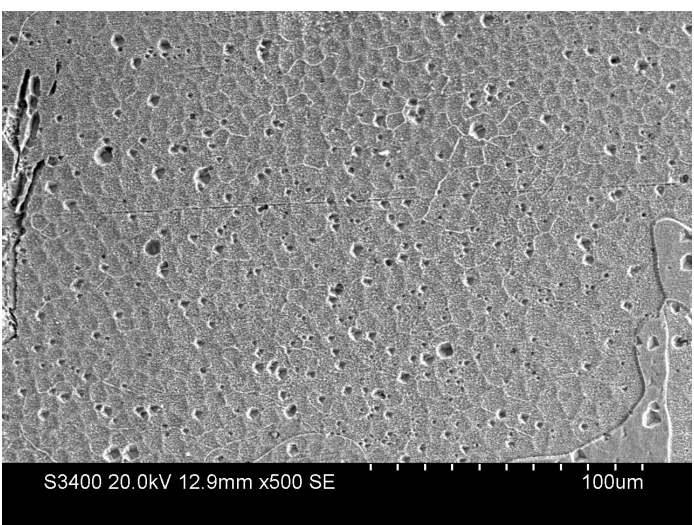

(a)

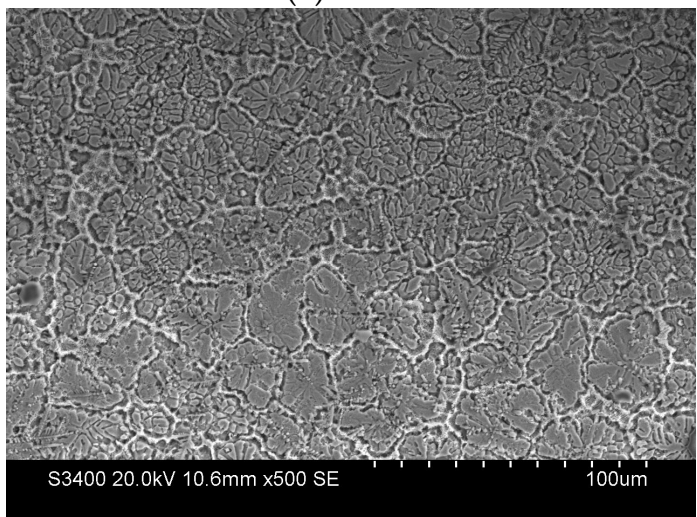

(c)

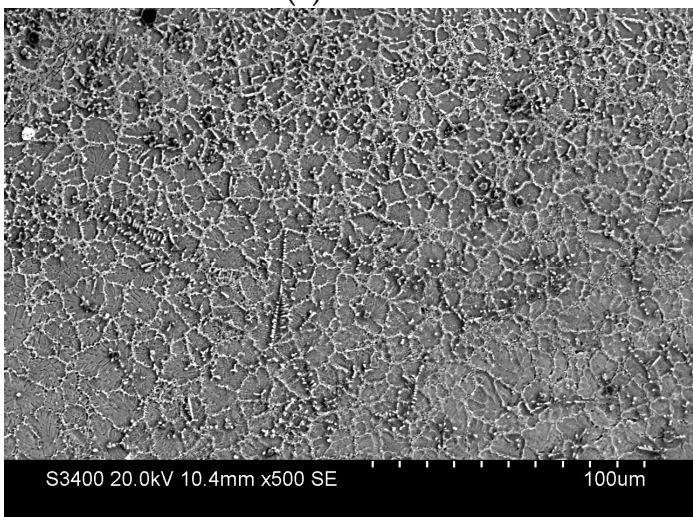

(e)

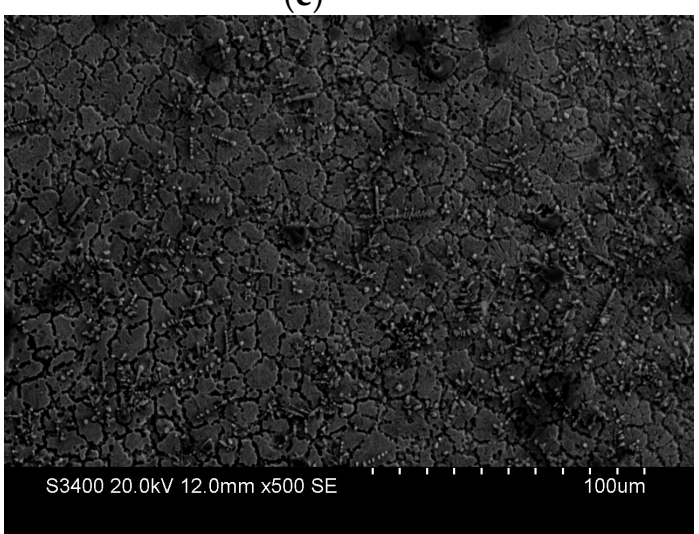

(g)

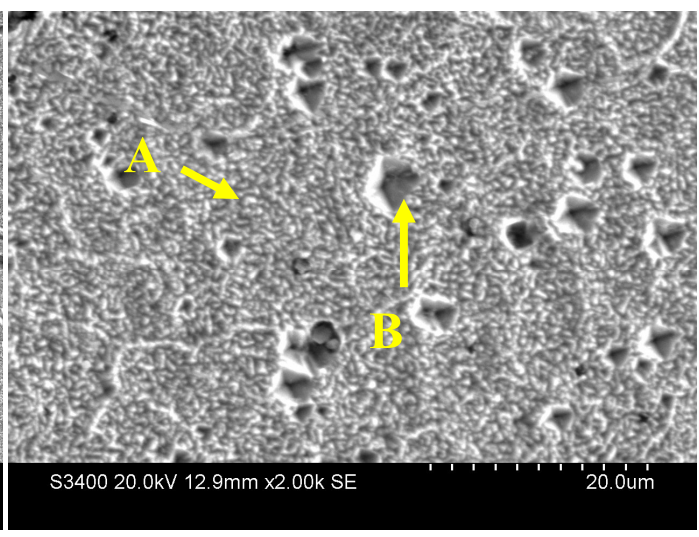

(b)

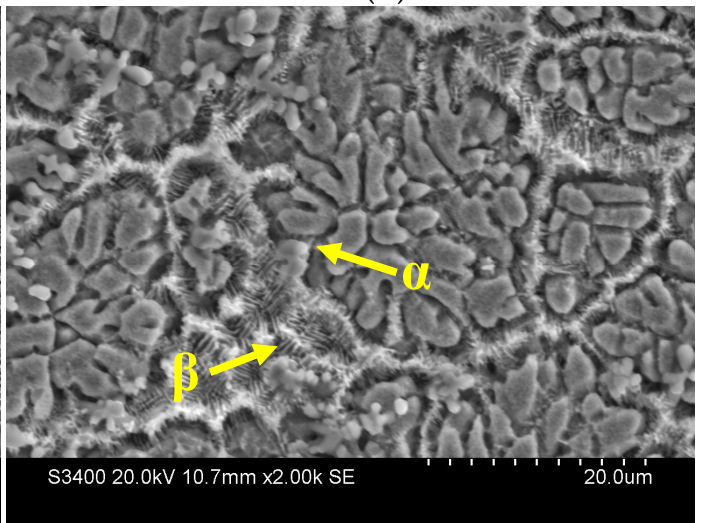

(d)

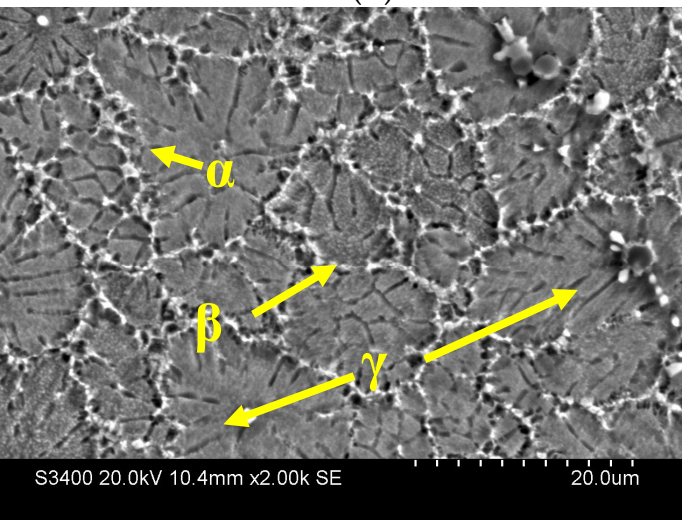

(f)

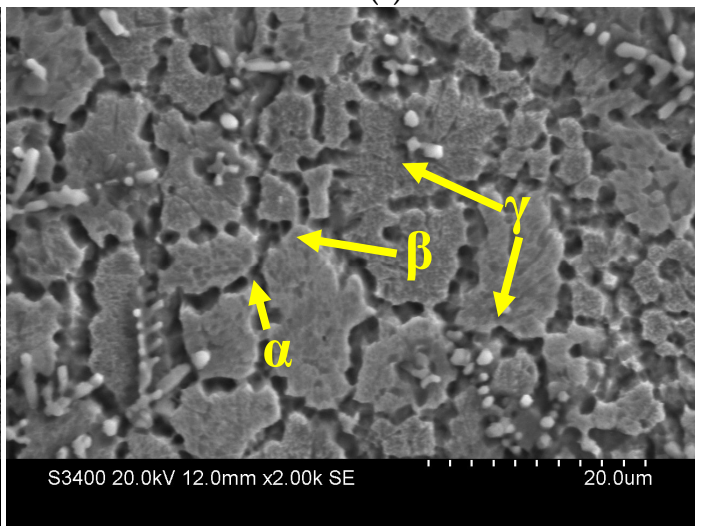

(h)

Figure 2. Cont. 


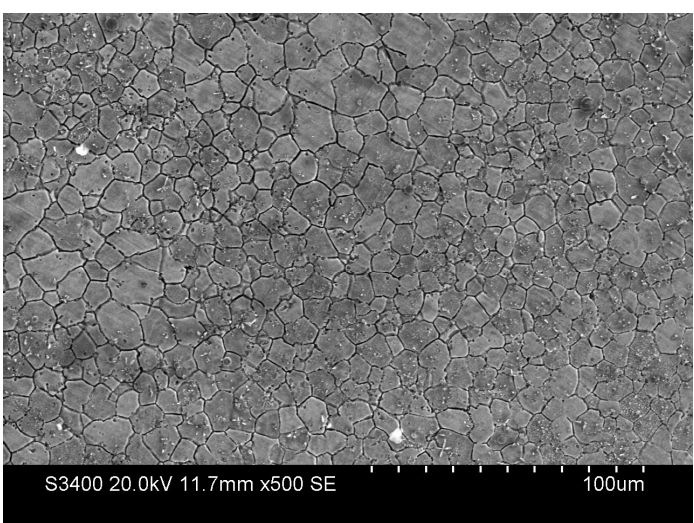

(i)

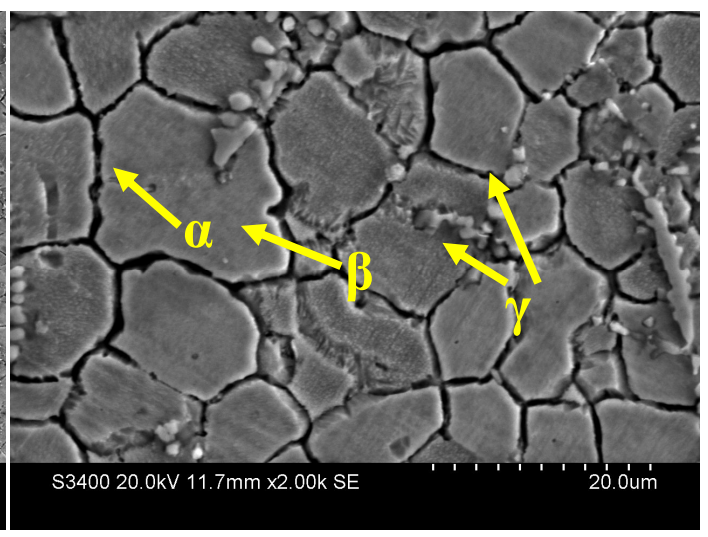

(j)

Figure 2. Cross-sectional SEM images of FeCoCrNiAlTi $x$ HEA coatings. $(\mathbf{a}, \mathbf{b}) x=0 ;(\mathbf{c}, \mathbf{d}) x=0.25 ;(\mathbf{e}, \mathbf{f})$ $x=0.5 ;(\mathbf{g}, \mathbf{h}) x=0.75 ;(\mathbf{i}, \mathbf{j}) x=1$.

Table 1. The chemical composition (at.\%) in different regions, as marked in Figure 2.

\begin{tabular}{cccccccc}
\hline $\boldsymbol{X}$ & Zone & $\mathbf{F e}$ & $\mathbf{C o}$ & $\mathbf{C r}$ & $\mathbf{N i}$ & $\mathbf{A l}$ & $\mathbf{T i}$ \\
\hline \multirow{2}{*}{0} & A & 32.26 & 24.84 & 10.76 & 23.54 & 8.60 & 0 \\
& $\mathrm{~B}$ & 32.80 & 23.78 & 11.58 & 23.56 & 8.28 & 0 \\
\hline \multirow{2}{*}{0.25} & $\alpha$ & 21.26 & 27.95 & 16.93 & 24.24 & 4.79 & 4.83 \\
& $\beta$ & 22.15 & 29.38 & 21.08 & 20.34 & 0.91 & 6.14 \\
\hline \multirow{3}{*}{0.5} & $\alpha$ & 29.15 & 20.12 & 10.80 & 25.31 & 5.47 & 9.16 \\
& $\beta$ & 30.12 & 20.54 & 12.69 & 23.11 & 1.72 & 11.81 \\
& $\gamma$ & 15.55 & 13.48 & 10.23 & 14.31 & 2.12 & 44.31 \\
\hline \multirow{3}{*}{0.75} & $\alpha$ & 33.75 & 18.03 & 12.58 & 19.71 & 4.13 & 11.83 \\
& $\beta$ & 39.73 & 19.31 & 14.30 & 11.21 & 2.74 & 12.72 \\
& $\gamma$ & 8.75 & 10.15 & 4.05 & 8.03 & 1.55 & 67.48 \\
\hline \multirow{2}{*}{1} & $\alpha$ & 33.52 & 15.82 & 10.55 & 20.24 & 6.76 & 13.11 \\
& $\beta$ & 37.12 & 17.01 & 12.58 & 15.33 & 1.59 & 16.36 \\
& $\gamma$ & 11.05 & 6.64 & 5.42 & 0 & 2.67 & 74.22 \\
\hline
\end{tabular}

The mixing enthalpy of atomic pairs between these six elements is listed in Table 2. As shown in Table 2, the mixing enthalpy of $\mathrm{Al}-\mathrm{Ni}$ is $-22 \mathrm{~kJ} / \mathrm{mol}$, so they have a good miscibility. However, the mixing enthalpies of $\mathrm{Fe}-\mathrm{Al}$ and $\mathrm{Cr}-\mathrm{Al}$ are $-11 \mathrm{~kJ} / \mathrm{mol}$ and $-10 \mathrm{~kJ} / \mathrm{mol}$, respectively, which is relatively high among all of the pairs between $\mathrm{Al}$ and other elements. Therefore, $\mathrm{Fe}, \mathrm{Cr}$, and $\mathrm{Al}$ cannot have a good miscibility. Thus, $\mathrm{Ni}, \mathrm{Al}$ and $\mathrm{Fe}, \mathrm{Cr}$ segregate in different phases. According to the EDS results, the phase $\beta$ is a Ti-enriched phase, indicating that the solid solubility of Ti in phase $\beta$ is higher than that in phase $\alpha$. This result is in accordance with Shun et al. [15]. With the addition of Ti, the content of eutectic phase $\beta$ decreases during the increase of proeutectic phase $\alpha$. Thus, the eutectic point of $\mathrm{BCC}_{1}$ and $\mathrm{BCC}_{2}$ is between $x=0$ and $x=0.25$. As Ti content increases to $x=0.5$, some fine precipitates are precipitated out and the main component is Ti. The precipitates can hinder the dislocation glide, thereby enhancing the hardness and the strength. At $x=1$, equiaxed and fine grained microstructure is obtained in the structure and the eutectic phase $\beta$ almost disappears.

Table 2. The mixing enthalpy of atomic pairs between these six elements $(\mathrm{kJ} / \mathrm{mol})$ [16].

\begin{tabular}{ccccccc}
\hline Element & Fe & Co & Cr & Ni & Al & Ti \\
\hline $\mathrm{Fe}$ & 0 & - & - & - & - & - \\
$\mathrm{Co}$ & -1 & 0 & - & - & - & - \\
$\mathrm{Cr}$ & -1 & -4 & 0 & - & - & - \\
$\mathrm{Ni}$ & -2 & 0 & -7 & 0 & - & - \\
$\mathrm{Al}$ & -11 & -19 & -10 & -22 & 0 & - \\
$\mathrm{Ti}$ & -17 & -28 & -7 & -35 & -30 & 0 \\
\hline
\end{tabular}


Although there are several principle elements, the phase composition of the HEAs is relatively simple. There are only a few kinds of solid solutions in the coatings. The phase number of FeCoCrNiAlTi $x$ HEA coatings in this paper is much less than that calculated by the Gibbs phase rule. This phenomenon can be attributed to the high entropy effect, which can restrain the formation of complex intermetallic compounds. Otto et al. [17] and Yao et al. [18] also found this phenomenon. According to the Gibbs free energy formula:

$$
\Delta G_{\text {mix }}=\Delta H_{\text {mix }}-T \Delta S_{\text {mix }}
$$

where $\Delta H_{\text {mix }}$ is the mixing enthalpy, $\Delta S_{\text {mix }}$ is the mixing entropy, and $T$ is the absolute temperature. It can be seen that the $\Delta G_{\text {mix }}$ will decrease if the $\Delta S_{\text {mix }}$ increases. The high $\Delta G_{\text {mix }}$ is the driving force for the formation of intermetallic compounds. Thus, the high entropy effect can decrease the $\Delta G_{\text {mix }}$ of the system and contribute to the formation of saturated or supersaturated solid solution, thereby enhancing the solution strength effect and the mechanical properties.

Figure 3 shows the results of the microhardness test along the cross section of the FeCoCrNiAlTi ${ }_{x}$ HEA coatings. The average microhardness of the HEA coatings at $x=0,0.25,0.5,0.75$, and 1 are 432.73 HV, 548.81 HV, 651.03 HV, 769.20 HV, and 966.29 HV, respectively. It is obvious that the average hardness of $\mathrm{FeCoCrNiAlTi}_{x}$ HEA coatings increases as the content of Ti increases. The average hardness reaches its maximum point for the HEA at $x=1$, which is more than twice that of the HEA at $x=0$. The content of $\mathrm{Ti}$ in $\mathrm{BCC}_{1}$ and $\mathrm{BCC}_{2}$ persistently increases (as shown in Figure 1) with the continuous addition of Ti. The atomic radii of $\mathrm{Fe}, \mathrm{Co}, \mathrm{Ni}, \mathrm{Cr}, \mathrm{Al}$, and $\mathrm{Ti}$ are $124 \mathrm{pm}, 125$ pm, $121 \mathrm{pm}, 124$ pm, $143 \mathrm{pm}$, and $145 \mathrm{pm}$, respectively. It was easily observed that the radius of Ti is the highest among all elements. With the addition of $\mathrm{Ti}$, the solid solute effect increases, leading to serious lattice distortion. Thus, the solid solution strengthening effect of Ti may be the most important reason, which contributes to the increase in hardness. In addition, the second phase strengthening effect caused by the separation of $\mathrm{Ti}$ is also an important reason. It can be seen in Figure 3 that there is a softening region near the fusion line between the coating and the substrate. In this zone, the grains are coarse, which affect the mechanical properties of the coatings.

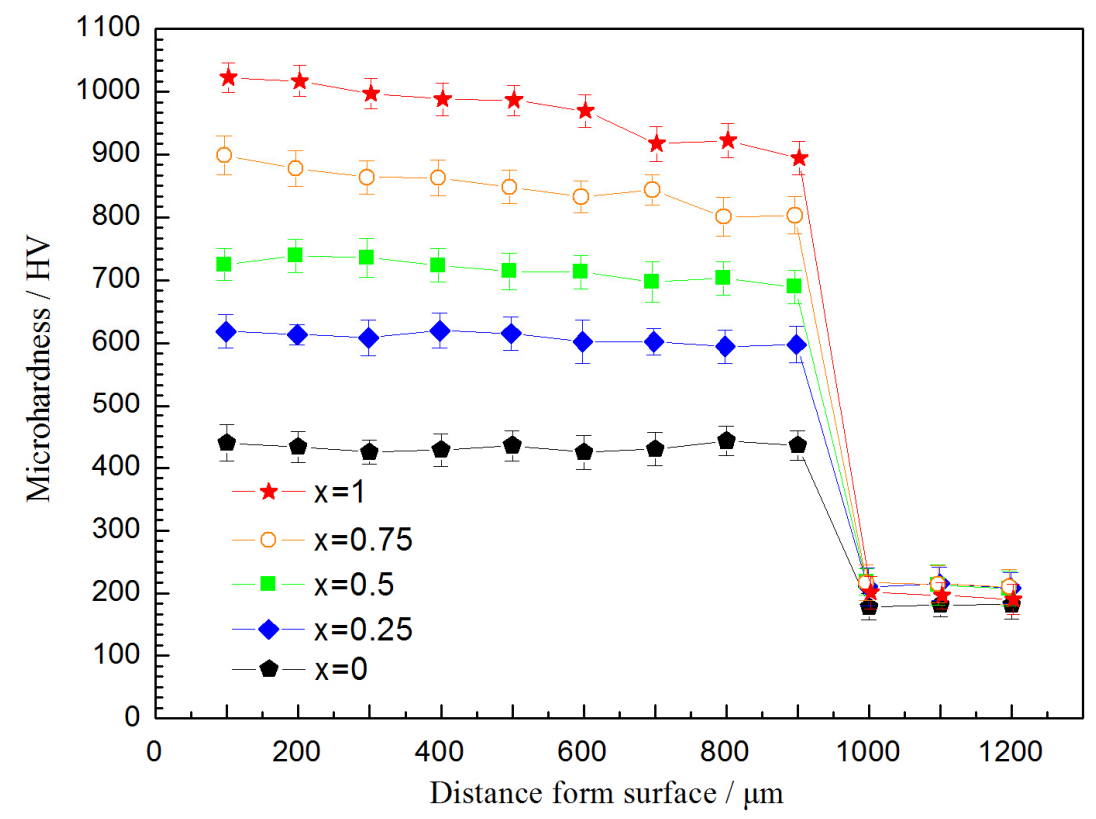

Figure 3. Results of the microhardness test along the cross section of the FeCoCrNiAlTi $x$ HEA coatings. 


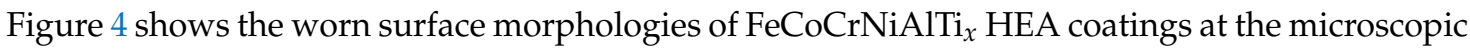
level. The surface tends to be smooth with the addition of Ti. Typically, the abrasion rate is connected with the resistance force at the contact surface during wear [19]. A higher resistance force usually leads to a higher abrasion rate. Figure 5 shows the variations in the friction coefficient curves of FeCoCrNiAlTi $x$ coating as a function of wear test time. The mass loss is proportional to the friction coefficient in Figure 6. According to the surface morphology, there are no obvious pits or other morphology features of adhesive wear. There are grooves and debris on the worn surface. Thus, the worn mechanism is the abrasive wear. At $x=0$, the grooves are deep, and there is substantial debris. The mass loss is also higher for the HEA at $x=0$, so the wear resistance is lower compared to the HEAs with higher Ti concentrations. At $x=0.25$, the amount of debris decreases, and the grooves are shallow. It is obvious that the wear resistance of the coating is enhanced with the addition of Ti. At $x=0.5$ and 0.75 , the deep grooves disappear. At $x=1$, only a few shallow grooves can be seen, and there is no debris. The mass loss of FeCoCrNiAlTi $x$ coatings is the lowest at $x=1$, according to Figure 6, indicating optimum wear resistance.

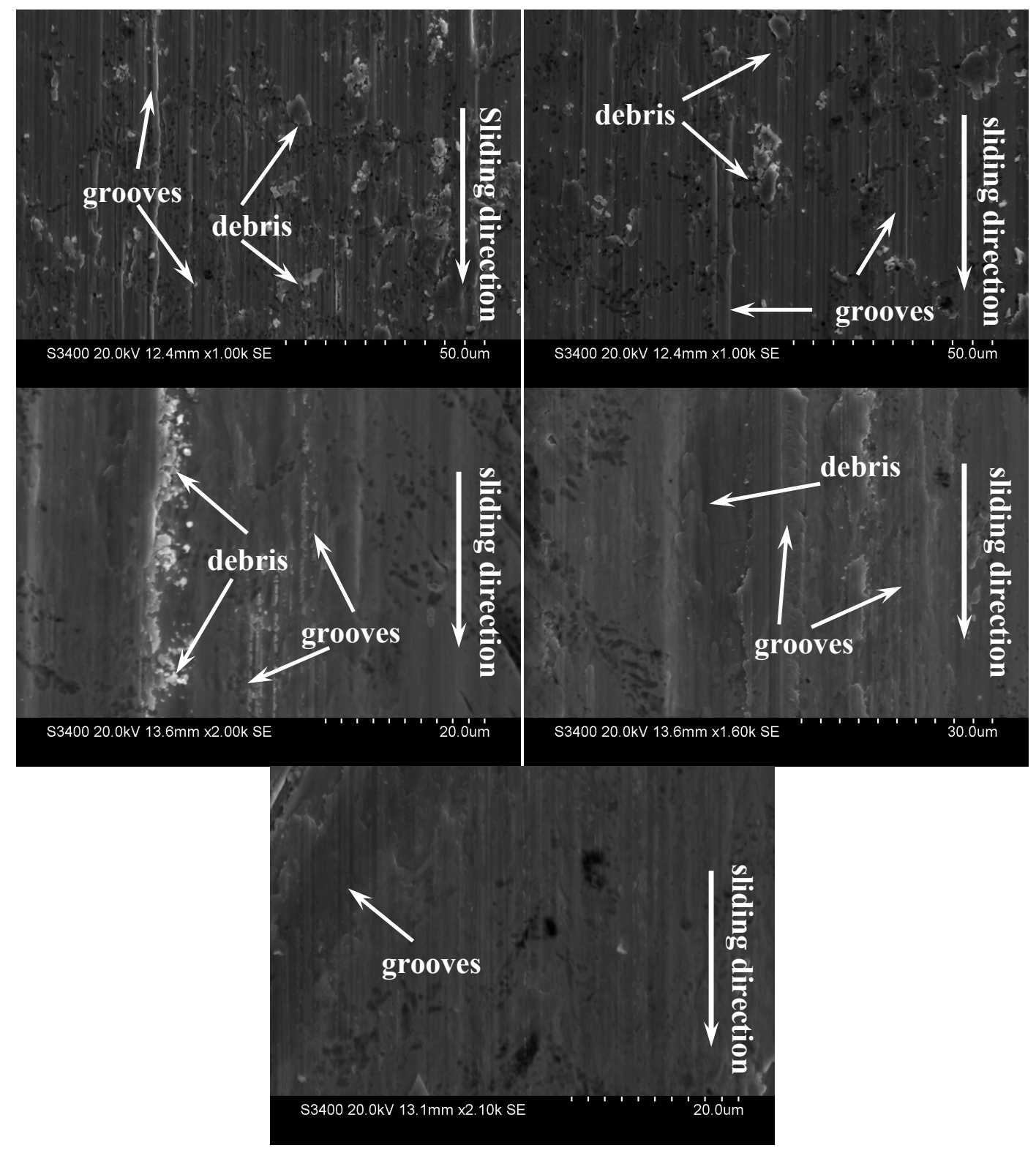

Figure 4. The morphology of FeCoCrNiAlTi $x$ HEA coatings after wear. 


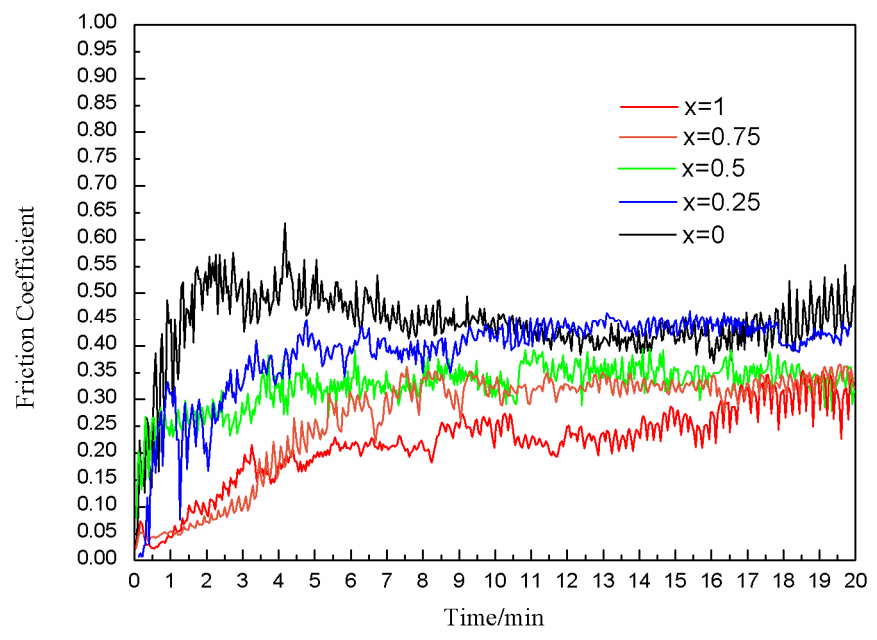

Figure 5. Friction coefficient of coating.

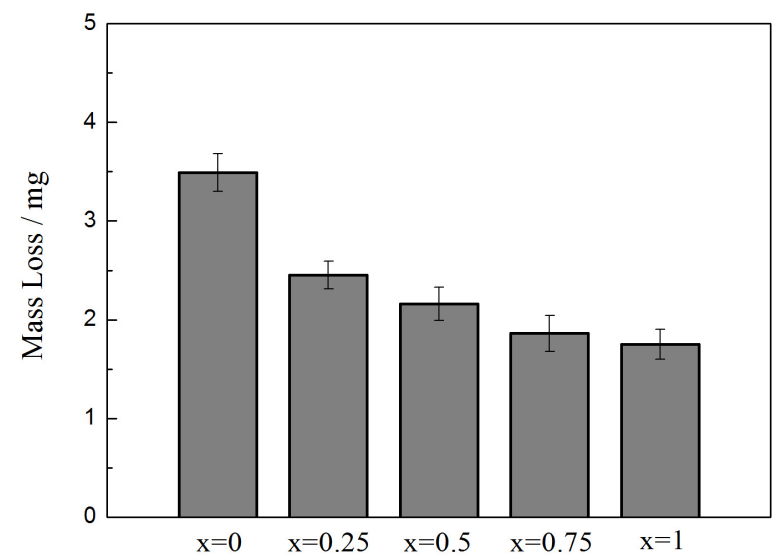

Figure 6. Mass loss of FeCoCrNiAlTi $x$ coatings.

\section{Conclusions}

After studying the effect of the content of $\mathrm{Ti}$ on the performance of $\mathrm{FeCoCrNiAlTi}_{x}$, three conclusions can be drawn as follows:

- The structure of FeCoCrNiAlTi $x_{x}$ coatings consists of two kinds of BCC phases. With the continuous increase in Ti content, the number of eutectic structure decreases, accompanying the increase in the proeutectic phase and the Ti-rich second phase is precipitated out. The eutectic point of $\mathrm{BCC}_{1}$ and $\mathrm{BCC}_{2}$ is between $x=0$ and $x=0.25$.

- The solution strength effect and the second phase strengthening effect on FeCoCrNiAlTi $x_{x}$ coatings are enhanced as Ti content increases. The average microhardness is also increased.

- The friction coefficient of FeCoCrNiAlTi $x$ coatings decreases as Ti content increases, while the wear resistance increases. The HEA coatings at $x=1$ exhibit the best wear resistance among the tested samples.

Acknowledgments: This work was financially supported by the Natural Science Foundation of Liaoning Province (No. 201602553), the Chinese National Natural Science Foundation (No. 51301112, No.51401129), and the China Postdoctoral Science Foundation (2015M 571327).

Author Contributions: Bin He performed the experiments and wrote the manuscript; Nannan Zhang designed the experimental process; Danyang Lin analyzed the data; Yue Zhang assisted in SEM analysis; Fuyu Dong assisted in paper review; Deyuan Li guided the direction of the research.

Conflicts of Interest: The authors declare no conflict of interest. 


\section{References}

1. Shen, W.J.; Tsai, M.H.; Yeh, J.W. Machining performance of sputter-deposited $\left(\mathrm{Al}_{0.34} \mathrm{C}_{\mathrm{r} 0.22} \mathrm{Nb}_{0.11} \mathrm{Si}_{0.11} \mathrm{Ti}_{0.22}\right)_{50} \mathrm{~N}_{50}$ high-entropy nitride coatings. Coatings 2015, 5, 312-325. [CrossRef]

2. Zhang, Y.; Zuo, T.T.; Tang, Z.; Gao, C.; Dahmen, K.A.; Liaw, P.K.; Lu, Z.P. Microstructures and properties of high-entropy alloys. Prog. Mater. Sci. 2014, 61,1-93. [CrossRef]

3. Gludovatz, B.; Hohenwarter, A.; Catoor, D.; Chang, E.H.; George, E.P.; Ritchie, R.O. A fracture-resistant high-entropy alloy for cryogenic applications. Science 2014, 345, 1153-1158. [CrossRef] [PubMed]

4. He, Y.Z.; Zhang, J.L.; Zhang, H.; Song, G.S. Effects of different levels of boron on microstructure and hardness of $\mathrm{CoCrFeNiAl}_{x} \mathrm{Cu}_{0.7} \mathrm{Si}_{0.1}$ by high-entropy alloy coatings by laser cladding. Coatings 2017, 7, 7. [CrossRef]

5. Tsai, M.H.; Yeh, J.W. High-entropy alloys: A critical review. Mater. Res. Lett. 2014, 2, 107-123. [CrossRef]

6. Yeh, J.W. Physical Metallurgy of High-Entropy Alloys. JOM 2015, 67, 2254-2261. [CrossRef]

7. Duan, H.; Wu, Y.; Hua, M.; Yuan, C.Q.; Wang, D.; Tu, J.S.; Kou, H.C.; Li, J. Tribological properties of AlCoCrFeNiCu high-entropy alloy in hydrogen peroxide solution and in oil lubricant. Wear 2013, 297, 1045-1051. [CrossRef]

8. Tian, F.Y.; Varga, L.K.; Chen, N.X.; Shen, J.; Vitos, L. Empirical design of single phase high-entropy alloys with high hardness. Intermetallics 2015, 58, 1-6. [CrossRef]

9. Chen, X.Y.; Yan, L.; Karnati, S.; Zhang, Y.L.; Liou, F. Fabrication and characterization of $\mathrm{Al}_{x} \mathrm{CoFeNiCu}_{1-x}$ high entropy alloys by laser metal deposition. Coatings 2017, 7, 47. [CrossRef]

10. An, X.; Liu, Q.; Zheng, B. Microstructure and properties of laser cladding high entropy alloy $\mathrm{MoFeCrTiWAl}_{x} \mathrm{Si}_{y}$ coating. Infra. Laser Eng. 2014, 43, 1140-1144.

11. Zhang, C.; Wu, G.F.; Dai, P.Q. Phase transformation and aging behavior of $\mathrm{Al}_{0.5} \mathrm{CoCrFeNiSi}_{0.2}$ high-entropy alloy. J. Mater. Eng. Perform. 2015, 24, 1918-1925. [CrossRef]

12. Tang, Z.; Gao, M.C.; Diao, H.Y.; Yang, T.F.; Liu, J.P.; Zuo, T.T; Zhang, Y.; Lu, Z.P.; Cheng, Y.Q.; Zhang, Y.W.; et al. Aluminum alloying effects on lattice types, microstructures, and mechanical behavior of high-entropy alloys system. JOM 2013, 65, 1848-1858. [CrossRef]

13. Jiao, Z.M.; Ma, S.G.; Chu, M.Y.; Yang, H.J.; Wang, Z.H; Zhang, Y.; Qiao, J.W. Superior mechanical properties of $\mathrm{AlCoCrFeNiTi}_{x}$ high-entropy alloys upon dynamic loading. J. Mater. Eng. Perform. 2016, 25, 451-456. [CrossRef]

14. Wang, Q.; Ma, Y.; Jiang, B.B.; Li, X.N.; Shi, Y.; Dong, C.; Liaw, P.K. A cuboidal B2 nanoprecipitation-enhanced body-centered-cubic alloy $\mathrm{Al}_{0.7} \mathrm{CoCrFe}_{2} \mathrm{Ni}$ with prominent tensile properties. Scripta Mater. 2016, 120, 85-89. [CrossRef]

15. Shun, T.T.; Hung, C.H.; Lee, C.F. The effects of secondary elemental Mo or Ti addition in $\mathrm{Al}_{0.3} \mathrm{CoCrFeNi}$ high-entropy alloy on age hardening at $700{ }^{\circ} \mathrm{C}$. J. Alloys Compd. 2010, 495, 55-58. [CrossRef]

16. Takeuchi, A.; Inoue, A. Classification of bulk metallic glasses by atomic size difference, heat of mixing and period of constituent elements and its application to characterization of the main alloying element. Mater. Trans. 2005, 46, 2817-2829. [CrossRef]

17. Otto, F.; Dlouhý, A.; Pradeep, K.G; Kuběnová, M.; George, E.P. Decomposition of the single-phase high-entropy alloy CrMnFeCoNi after prolonged anneals at intermediate temperatures. Acta Mater. 2016, 112, 40-52. [CrossRef]

18. Yao, M.J.; Pradeep, K.G.; Tasan, C.C.; Raabe, D. A novel, single phase, non-equiatomic FeMnNiCoCr high-entropy alloy with exceptional phase stability and tensile ductility. Scripta Mater. 2014, 72-73, 5-8. [CrossRef]

19. Yu, Y.; Liu, W.; Zhang, T.; Li, J.; Wang, J.; Kou, H.; Li, J. Microstructure and tribological properties of AlCoCrFeNiTi 0.5 , high-entropy alloy in hydrogen peroxide solution. Metall. Mater. Trans. A 2014, 45, 201-207. [CrossRef]

(C) 2017 by the authors. Licensee MDPI, Basel, Switzerland. This article is an open access article distributed under the terms and conditions of the Creative Commons Attribution (CC BY) license (http://creativecommons.org/licenses/by/4.0/). 